\title{
Three-Dimensional Numerical Modeling of a Deep Excavation Adjacent to Shanghai Metro Tunnels
}

\author{
Y.M. Hou, J.H. Wang, and L.L. Zhang \\ Civil Engineering Department, Shanghai Jiaotong University, 1954 Hua Shan Road, \\ Shanghai, China \\ \{ymhou, wjh417, lulu_zhang\}asjtu.edu.cn
}

\begin{abstract}
Due to rapid construction and limited urban area in Shanghai, some deep excavations are very close to the existing metro tunnels or sensitive superstructures. Therefore the safety of the adjacent tunnels and surrounding structures become an important issue during design and construction of these deep excavations. This paper presents a 3D finite-element modeling using the finite element analysis program ABAQUS for an oversize deep excavation in Shanghai soft deposits. The excavation is the excavation of the north square underground shopping center of Shanghai South Railway Station. Two cases of numerical analyses assuming anisotropic and isotropic soil stiffness respectively are conducted. The estimated wall deflection and ground movements are compared with the field monitoring results. It is found that soil stiffness anisotropy has a significant effect on the accuracy of prediction of the diaphragm wall deflection and the ground movement around excavation for the oversize excavation in Shanghai soft deposits. The calculated ground movements of the anisotropic case agree well with the field measurements.
\end{abstract}

Keywords: numerical modeling, excavation, ground movement, anisotropic stiffness.

\section{Introduction}

To meet the increasing demand for economic growth, extensive underground structures and metro systems have been rapidly constructed in Shanghai. Some of these excavations are very close to the existing metro tunnels or sensitive superstructures. The safety of the adjacent tunnels and surrounding structures may be affected by the ground movement induced by the excavation. The excavation of the north square underground shopping center of Shanghai South Railway Station is one of the deep excavations under complicated conditions in the urban area of Shanghai. The site is located in the south of the city. It was only about $3 \mathrm{~m}$ away from the existing tunnels of Shanghai Metro Lines No.1 and No.3. The minimum distance between the excavation and the tunnels of the new route of Shanghai Metro Line No.1 was only $2 \mathrm{~m}$. In addition, the excavation of the interchange station of Metro Lines No.1 and No.3 was 
located besides this excavation in northwest and was constructed before this excavation. The retaining structures of the two excavations were shared. Therefore, it is important to predict the ground movement accurately in order to assess the impact of the excavation on the metro tunnels and the existing excavation nearby.

Finite-element analyses have been used to study the performance of excavations as the soil stress-strain behaviors can be considered and the construction sequences can be modeled in the numerical modeling $[3,4,6,8,10]$. The constitutive models of soils are most important in numerical analyses. Researchers showed that anisotropic stress-strain strength of soft clays and nonlinear stiffness properties at small shear strains have significant effect on the predicted wall deflections and soil movements [7]. Generally, soils in Shanghai are sedimentary soils which are deposited through the process of sedimentation followed by consolidation under accumulative overburden pressures. Therefore, it may improve the prediction of ground movements induced by excavation if considering the soils as anisotropic materials. In this paper, the excavation of the North Square of Shanghai South Railway Station is studied by a three-dimensional finite element modeling. Numerical analyses are conducted to study the effect of anisotropic stiffness of soils on the computed ground deformation around the excavation. The wall deflection and ground settlement for an isotropic case and an anisotropic case are presented and compared with the field monitoring measurements.

\section{Site Description and Ground Conditions}

The site in this paper is the excavation site of the north square underground shopping center of Shanghai South Railway Station, which is located in the south of Shanghai. Fig. 1 shows the layout of the excavation. The area of the site was about $40,000 \mathrm{~m}^{2}$. The excavation was only about $3 \mathrm{~m}$ away from the existing tunnels of Shanghai Metro Line No. 1 and No. 3, which were in the northwest and northeast side of the excavation, respectively. The new route of Shanghai Metro Line No. 1 was in the east of the site. The minimum distance between the excavation and the tunnels was only $2 \mathrm{~m}$.

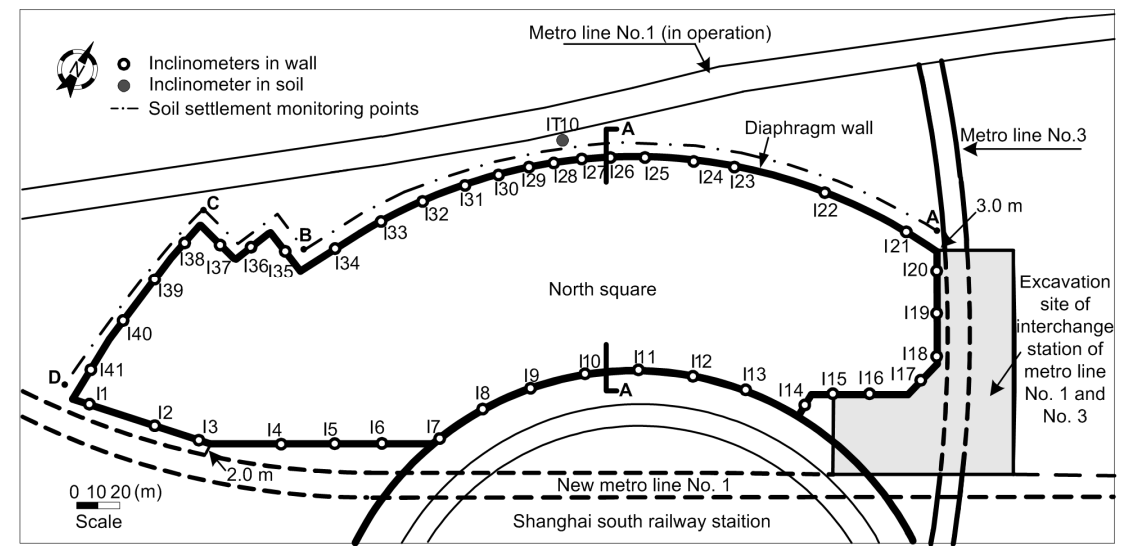

Fig. 1. The location and instrumentation of the excavation site 


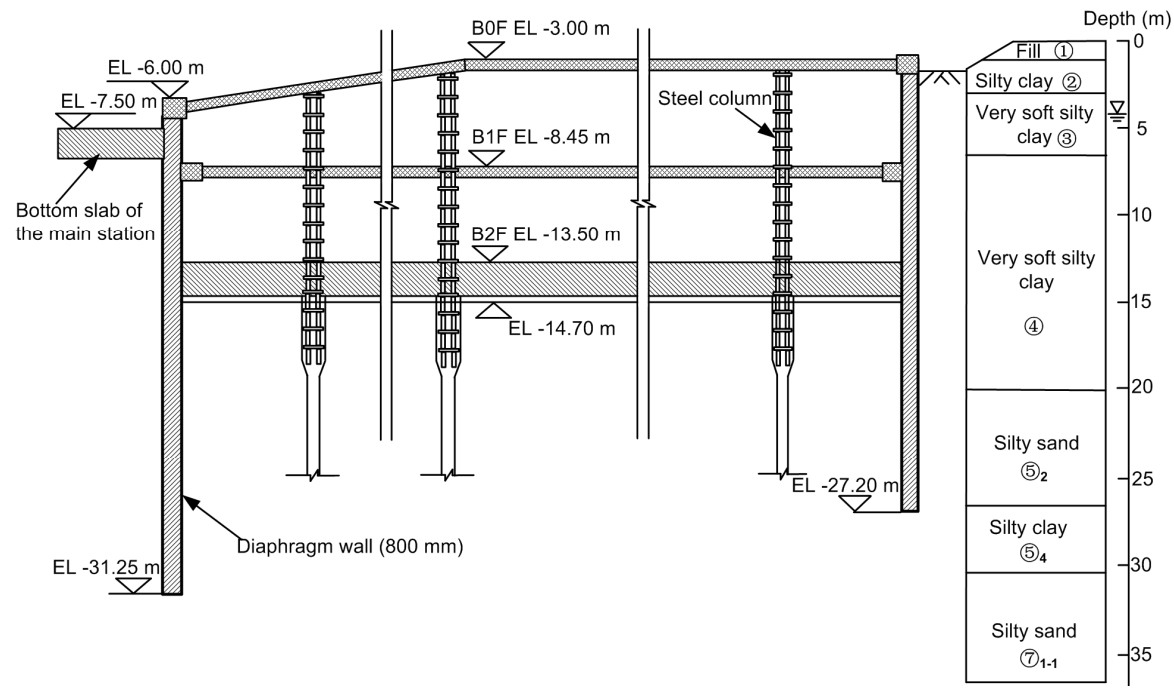

Fig. 2. Cross Section A-A of the excavation

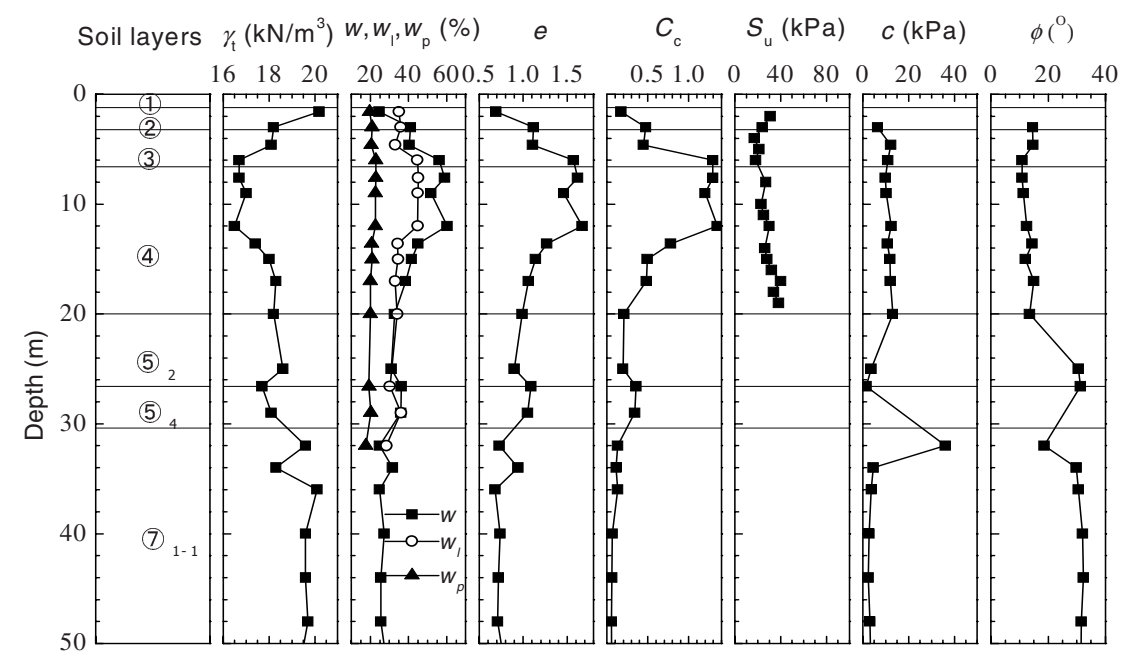

Fig. 3. Soil profiles and variation of soil properties with depth

To monitor the performance of the excavation, a comprehensive monitoring system was installed on site. As shown in Fig. 1, forty one inclinometers I1 I41 were installed in the diaphragm walls to measure the rotation and deflections of the walls. The inclinometer IT10 was installed adjacent to Line No. 1 to monitor the lateral displacement induced by the excavation in the soil. Thirty one surface settlement points were installed along the west boundary of the excavation (from point A to B to $\mathrm{C}$ to $\mathrm{D})$. The excavation was $12.5 \mathrm{~m}$ deep with two basement levels as shown in Fig. 2 
and was constructed using the top-down method. The concrete floor slabs were located at elevations of $-3 \mathrm{~m},-8.45 \mathrm{~m}$ and $-14.7 \mathrm{~m}$, respectively. The excavation was supported by a $0.8 \mathrm{~m}$ thick concrete diaphragm wall. The depths of the walls were 24 $\mathrm{m}$ to $27.85 \mathrm{~m}$. The site of the interchange station of Metro Line No. 1 and No. 3 was adjacent to the excavation site and the retaining structures between the two excavations were diaphragm walls.

The site is underlain by thick, relatively soft Quaternary alluvial and marine deposits. Fig. 3 illustrates the succession of soil layers and the variation of soil properties with depth. The soil properties include total unit weight, water contents, void ratio, compression index, field vane shear strength, cohesion and friction angle.

\section{Numerical Modeling of the Excavation}

\subsection{Finite Element Mesh and Boundary Conditions}

In this paper, the finite element analysis program ABAQUS is used to conduct numerical modeling. The meshes of the entire 3D-finite element model $(1200 \mathrm{~m} \times 500$ $\mathrm{m} \times 80 \mathrm{~m}$ ) and the retaining structures are shown in Fig. 4. The three-dimensional solid elements were used for soil layers. The columns and girders of the structure are simulated by beam elements. The diaphragm walls and concrete floor slabs are modeled using shell elements. The entire 3-D model consists of 178,162 nodes and 155,160 elements. The four side boundary surfaces are fixed along the vertical direction and the direction perpendicular to each surface. The bottom boundary is fixed in all $\mathrm{x}, \mathrm{y}$ and $\mathrm{z}$ directions.

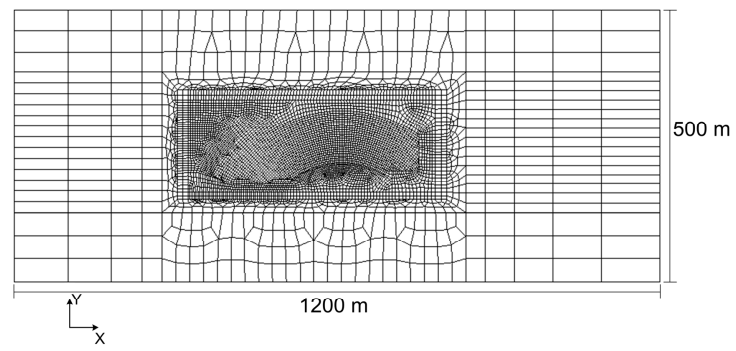

(a) plan view of the mesh in the $x-y$ plane

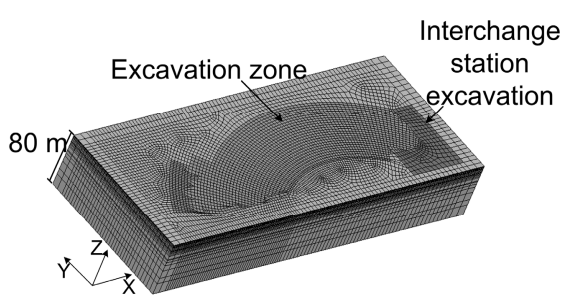

(b) 3D mesh of the excavation

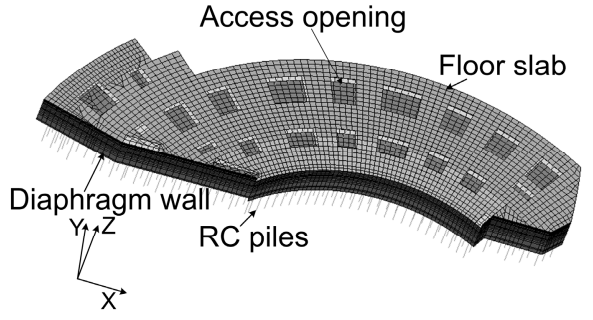

(c) mesh of retaining structures

Fig. 4. Mesh of the 3D finite-element model 


\subsection{Soil Model and Parameters}

In the numerical analyses, the diaphragm walls, the steel columns, the RC piles of the foundation and the floor slabs are assumed to be linear-elastic materials with the Young's modulus of $30 \mathrm{GPa}$ and the Poisson's ratio of 0.2 .

The numerical modeling includes establishment of the 3-D finite element mesh of the complex shaped excavation with foundation piles and the detailed construction process such as installing piles and retaining structures and zoned excavation is also needed to be modeled. Therefore, it is reasonable to model soils as elastic materials considering the complication and difficulties of modeling and the cost of computation time. As the soils in the site are generally Quaternary alluvial and marine soils deposited through the process of sedimentation followed by consolidation in horizontal layers, two cases with isotropic and anisotropic soil properties are conducted to study the effect of soil stiffness anisotropy. In the anisotropic case, it is assumed that the soils are cross-anisotropic, in which the inherent anisotropy is considered but the stress-induced anisotropy of the soil and the changes of the degree of anisotropy due to excavation are ignored. For an idealized cross-anisotropic elastic material, the stress-strain behavior is governed by five independent elastic parameters: $E_{h}, E_{v}, G_{v h}, v_{v h}$ and $v_{h h}$, where $E_{h}$ and $E_{v}$ are the Young's moduli in the horizontal and vertical directions, respectively; $G_{v h}$ is the shear modulus in any vertical plane; $v_{h h}$ is the Poisson's ratio for the effect of horizontal strain on the complementary horizontal strain; and $v_{v h}$ is the Poisson's ratio for the effect of vertical strain on horizontal strain. As the stress paths of the soil around the deep excavation correspond approximately to triaxial extension, the extension moduli of the soils should be used in the numerical analyses of excavation.

Table 1. Soil parameters used in numerical analysis

\begin{tabular}{ccccccccc}
\hline $\begin{array}{c}\text { Layer } \\
\text { No. }\end{array}$ & $\begin{array}{c}\gamma_{t} \\
\left(\mathrm{kN} / \mathrm{m}^{3}\right)\end{array}$ & $K_{0}$ & $\begin{array}{c}E_{c} \\
(\mathrm{kPa})\end{array}$ & $\begin{array}{c}E_{h} \\
(\mathrm{kPa})\end{array}$ & $\begin{array}{c}E_{v} \\
(\mathrm{kPa})\end{array}$ & $\begin{array}{c}G_{v h} \\
(\mathrm{kPa})\end{array}$ & $v_{v h}$ & $v_{h h}$ \\
\hline (1) & 19.1 & 0.50 & 5530 & 13270 & 22120 & 6194 & 0.33 & 0.35 \\
$(2)$ & 19.5 & 0.50 & 3870 & 9280 & 15480 & 4024 & 0.29 & 0.30 \\
(3) & 17.8 & 0.55 & 3040 & 7290 & 12160 & 3162 & 0.33 & 0.35 \\
(4) & 17.0 & 0.64 & 2090 & 5000 & 8360 & 2174 & 0.37 & 0.42 \\
(5) $_{2}$ & 18.5 & 0.52 & 13750 & 33000 & 55000 & 14300 & 0.29 & 0.30 \\
(5) $_{4}$ & 24.3 & 0.43 & 20250 & 48600 & 81000 & 21060 & 0.29 & 0.30 \\
(7) $_{1-1}$ & 19.3 & 0.43 & -- & 120000 & 200000 & 520000 & 0.29 & 0.30 \\
\hline
\end{tabular}

Becker [1] summarized undrained anisotropic elastic parameters for various clays. The ratio of $E_{h} / E_{v}$ ranges from 0.5 to 2.4 , and the ratio of $G_{v h} / E_{v}$ ranges from 0.23 to 0.44. $\mathrm{Ng}$ [9] compared compression modulus and extension modulus under drained and undrained conditions. It shows the ratio of $E_{v} / E_{v}$ ' ranges from 0.26 to 0.54 , in which $E_{v}$ is the Young's modulus of compression condition and $E_{v}$ ' is the Young's modulus of extension condition. Lee [5] proposed that $G_{v h} / E_{v}$ should be $40 \%-100 \%$ of the value of $G / E$ under isotropic condition. Large numbers of back analyses for the excavations in Shanghai soft deposits indicate the vertical Young's modulus $E_{v}$ can be 
taken as $4 E_{c}$, in which $E_{c}$ is the modulus of compressibility. The modulus of compressibility in this study (Table 1 ) is adopted from the ground investigation report of the site. The ratios of $E_{h} / E_{v}$ and $G_{v h} / E_{v}$ of the soils in this study are assumed to be 0.6 and 0.26 , respectively. For the isotropic case, the Young's modulus $E$ is equal to $E_{v}$ and the Poisson's ratio $v$ is equal to $v_{h h}$ in Table 1 .

Table 2. Construction sequence of the excavation

\begin{tabular}{cl}
\hline Stage & Construction operation \\
\hline 1 & Construction of diaphragm walls and RC piles \\
2 & Excavation of the interchange station \\
3 & Excavation of Shanghai South Railway Station \\
4 & Excavate to $-3.75 \mathrm{~m}$ \\
5 & Construct the first floor slab and excavate to $-7.5 \mathrm{~m}$ \\
6 & Construct the second floor slab and excavate to $-13.0 \mathrm{~m}$ \\
7 & Excavate to $-14.7 \mathrm{~m}$ and construct the bottom floor slab \\
\hline
\end{tabular}

\subsection{Results and Discussion}

The deformation of the soil adjacent to Metro tunnels may induce significant effects on the Metro tunnels. Therefore, the soil deformation and structure displacement near the Metro tunnels are studied here in detail.

Fig. 5(a) and 5(b) illustrate the calculated and field measured deformation at Stage 7 for the inclinometers I29 and IT10, respectively. The two inclinometers are very close to the Metro Line No. 1. The maximum wall deflection occurs near the bottom of the excavation. It shows that the wall deflection increases significantly with the anisotropic soil stiffness parameters. The maximum computed wall deflection of the anisotropic case is $37.5 \mathrm{~mm}$, which is about $50 \%$ greater than that of the isotropic case. The maximum difference between measurements and the computed wall deflection of the anisotropic case is only $8 \%$, while the maximum difference between the measured and the computed deformation with the isotropic soil model is about $30 \%$. The calculated ratio of maximum measured lateral wall deflection to the excavation depth for the inclinometer I29 is $0.25 \%$, which is within the range of the reported values in [2]. For the anisotropic case and the isotropic case, the ratios of maximum wall deflection to the excavation depth are $0.25 \%$ and $0.18 \%$, respectively. It shows that the anisotropy of soil properties should be considered for a more accurate prediction of wall deflection.

The maximum value of the observed horizontal soil movement by IT10 is about 18 $\mathrm{mm}$, which is much smaller than the maximum wall deflection of the inclinometer I29. Therefore, the retaining structures of the excavation reduce the ground movement and the deformation of the operating tunnels of Metro Line No. 1 is well controlled. The computed maximum ground movement of the anisotropic case is $18.4 \mathrm{~mm}$, while the computed maximum ground movement of the isotropic case is only $14.7 \mathrm{~mm}$. It shows the numerical analysis with anisotropic soil parameters yield a more accurate estimation of the lateral ground movement. 
Fig. 6 presents the measured and calculated ground surface settlement along ABCD near the Metro Line No. 1 at Stage 7. The measured settlement is $10.8 \mathrm{~mm}$ to $16.75 \mathrm{~mm}$. The ground settlements near the corners of the excavation are generally larger than the settlement at other locations. This is probably due to the arching effect of the corner. The predicted ground settlement of the anisotropic case is slightly smaller than the observed settlement. However, the maximum difference between the computed settlement of the isotropic case and the measured values is approximately $50 \%$. It shows that the soil models with anisotropic stiffness could improve the accuracy of the prediction of the soil settlement around the excavation. The adopted soil parameters for the anisotropic elastic model are shown to be reasonable for Shanghai soils.

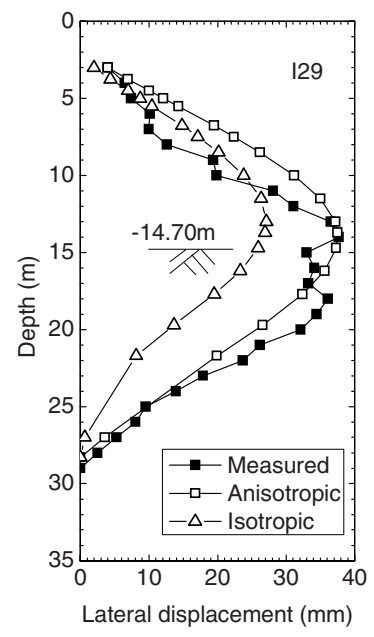

(a)

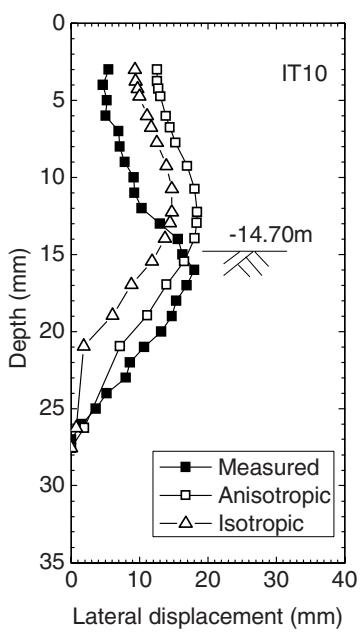

(b)

Fig. 5. Measured and calculated wall deflection and soil lateral displacement at Stage 7

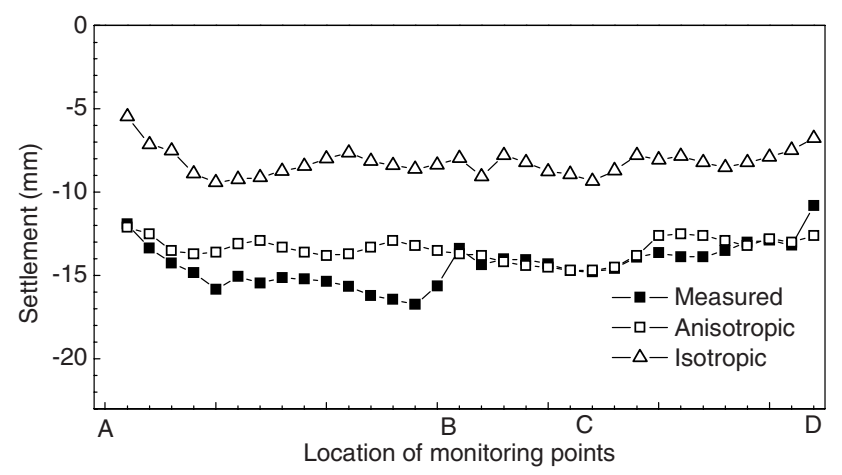

Fig. 6. Measured and calculated ground surface settlements at Stage 7 


\section{Conclusions}

In this paper, a three-dimensional finite-element modeling is conducted to study the performance and soil deformation of the excavation for the north square of Shanghai South Railway Station. Two cases of numerical analyses with isotropic and anisotropic soil stiffness parameters are conducted to study the effects of anisotropic stiffness. It shows the anisotropic stiffness has significant effects on the computed wall deflection and ground deformation induced by the excavation. The wall deflection and ground lateral movement of the anisotropic case are significantly larger than those obtained in the isotropic case. The use of the anisotropic soil model greatly improves the accuracy of the estimated wall deflection and soil deformation around excavation. The adopted soil parameters for the anisotropic elastic model in the numerical modeling are shown to be reasonable for Shanghai soils.

Acknowledgments. This study is substantially supported by Shanghai Municipal Sciences and Technology Committee (Grant No. 04DZ12001).

\section{References}

1. Becker, D. E.: Settlement Analysis of Intermittently-loaded Structures Founded on Clay Sub-soils. PhD thesis, University of Western Ontario (1981).

2. Clough, G. W., and O'Rourke, T. D.: Construction-induced Movements of In-situ Walls. In: Design and Performance of Earth Retaining Structures. Geotechnical Special Publication No. 25. ASCE. (1990) 439-470.

3. Clough, G. W., Weber, P. R., and Lamont, J.: Design and Observation of Excavation Support Systems by Iterative Design. In: Proc. ASCE Spec. Conf. on Perf. of Earth and Earth-supported Struct., ASCE, New York, N.Y. Vol. 1 (1972), 1367-1390.

4. Finno, R. J., and Harahap, I. S.: Finite Element Analysis of HDR-4 Excavation. Journal of Geotechnical Engineering, ASCE, 117(10) (1991), 1590-1609.

5. Lee, K.M., and Rowe, R. K.: Deformations Caused by Surface Loading and Tunneling: The Role of Elastic Anisotropy. Geotechnique, 39(1) (1989), 125-140.

6. Mana, A. I., and Clough, G. W.: Prediction of Movement for Braced Cut in Clay. Journal of Geotechnical Engineering, ASCE, 107(8) (1981), 759-777.

7. Ng, C. W. W., Leung, E. H. Y., and Lau, C. K.: Inherent Anisotropic Stiffness of Weathered Geomaterial and Its Influence on Ground Deformations around Deep Excavations. Canadian Geotechnical Journal, 41 (2004), 12-24.

8. Ng, C. W. W., Lings, M. L.: Effects of Modeling Soil Non-linearity and Wall installation on Back-analysis of Deep Excavation in Stiff Clay. Journal of Geotechnical \& Geoenvironmental Engineering, ASCE, 121(10) (1995), 687-695.

9. Ng, R. M. C.: Ground Reaction and Behaviour of Tunnels in Soft Clays. PhD thesis, University of Western Ontario (1984).

10. Ou, C. Y., Shiau, B. Y., and Wang, I. W.: Three-dimensional Deformation Behavior of The Taipei National Enterprise Center (TNEC) Excavation Case History. Canadian Geotechnical Journal, 37 (2000), 438-448. 